\title{
Sustaining the Earth's Watersheds- Agricultural Research Data System: Data development, user interaction, and operations management
}

E.J. Sadler, J.L. Steiner, J.-S. Chen, G. Wilson, J. Ross, T. Oster, D. James, B. Vandenberg, K. Cole, and J. Hatfield

\begin{abstract}
To support the USDA Agricultural Research Service Conservation Effects Assessment Project, a publicly available Web-based watershed data system, named Sustaining the Earth's Watersheds-Agricultural Research Data System (STEWARDS), was developed to provide data search, viewing, and downloading capabilities. The objectives of this paper are to (1) describe the data within STEWARDS, (2) describe the process of accessing watershed data and (3) provide an overview of the system management. STEWARDS is a data delivery system with a geographic information system interface, using space, time, and topic as key fields for searching an extensive database of soil, water, climate, land management, and socio-economic data from multiple long-term research watersheds. STEWARDS facilitates (1) researchers in obtaining USDA Agricultural Research Service historic watershed data for hydrological studies; (2) modelers in retrieving measured data over extensive time periods for model calibration and validation in watershed assessments to support CEAP; and (3) watershed managers, partners, and stakeholders in accessing long term data to support decisionmaking for selecting effective conservation practices.
\end{abstract}

Key words: Conservation Effects Assessment Project (CEAP)—database access and usedatabase operation-database structure-Sustaining the Earth's Watersheds-Agricultural Research Data System (STEWARDS)

The Sustaining the Earth's WatershedsAgricultural Research Data System (STEWARDS) database was developed to organize, store, and provide Web-based access to data from USDA Agricultural Research Service (ARS) benchmark watersheds associated with the Conservation Effects Assessment Project (CEAP) Cropland component and eventually other national projects. The CEAP network currently includes 14 instrumented long-term watersheds having, in some cases, more than 60 years of potentially available data. These watershed studies are spread over a range of geophysical contexts and were initiated independently by researchers studying problems at specific locations. Consequently, the data collected vary, the methods for collecting and storing the data vary, and insufficient (and variable) effort has been expended to store, organize, or deliver the data at the national level. As a result, data that are critical for the success of CEAP, or other hydrologic analyses, are not consistently available to users (Steiner et al. 2003).

Recognizing that data embodied in this network are now increasingly relevant to the CEAP, a team of researchers and information technology staff within CEAP was requested to create a database system capable of delivering the long-term USDA ARS watershed data for research purposes. This team is represented in the author list, and team operations necessary to achieve the objectives are described in Steiner et al. (2008). Here, our objectives are to (1) describe the data within STEWARDS, (2) describe the process of accessing watershed data and (3) provide an overview of the system management. Objectives 1 and 2 are necessarily sequential-an understanding of the data structure is required to understand the process of data query and extraction that the system provides.

STEWARDS Data Content. The characteristics of data expected to be stored posed two significant design challenges, including extreme flexibility and merging spatial and temporal data. The design would have to support the flexibility required by a research data system, given that the data varied in format and organization, depending upon year, topic, original data collector, instrumentation, computer platform, and other factors. Further, future needs cannot be predicted. Such flexibility requires that software and data rules or other constraints be minimized. On the other hand, certain consistencies in structure and format were required to enable the software to provide a consistent view of the data for every user.The flexibility requirement was addressed using two tables - a data table and a data definition table, which are described below. The second requirement, to link spatial data with temporal data, was problematic because tools built for the spatial domain generally do not handle temporal data well, and tools built for the temporal domain generally do not handle spatial data well. The link between these two types of data was addressed using a site identifier (SiteID) as a primary index in both domains. These two innovations may well be of general interest in other database projects.

While a detailed knowledge of the data structure will be essential for anyone who wants to provide data, a general understanding of the data structure will also be needed by those who will be querying the database. The following section describes sufficient details of the data structure so that a user can understand data obtained from STEWARDS.

Spatial Data. The data and metadata originating from or relating to the spatial

E. John Sadler is a soil scientist for the USDA Agricultural Research Service (ARS), Columbia, Missouri. Jean L. Steiner is a soil scientist and Jin-Song Chen is a research hydrologist for the USDA ARS, El Reno, Oklahoma. Greg Wilson is an IT specialist for the USDA ARS, Beltsville, Maryland. John Ross is an IT specialist for the USDA ARS, El Reno, Oklahoma. Teri Oster is an IT specialist for the USDA ARS, Columbia, Missouri. David James is a geographic information specialist for the USDA ARS, Ames, lowa. Bruce Vandenberg is an IT specialist for the USDA ARS, Fort Collins, Colorado. Kevin Cole is a watershed specialist and Jerry Hatfield is a plant physiologist for the USDA ARS, Ames, lowa. 


\section{Figure 1}

Watershed-level and site-level metadata and geospatial data components of STEWARDS.

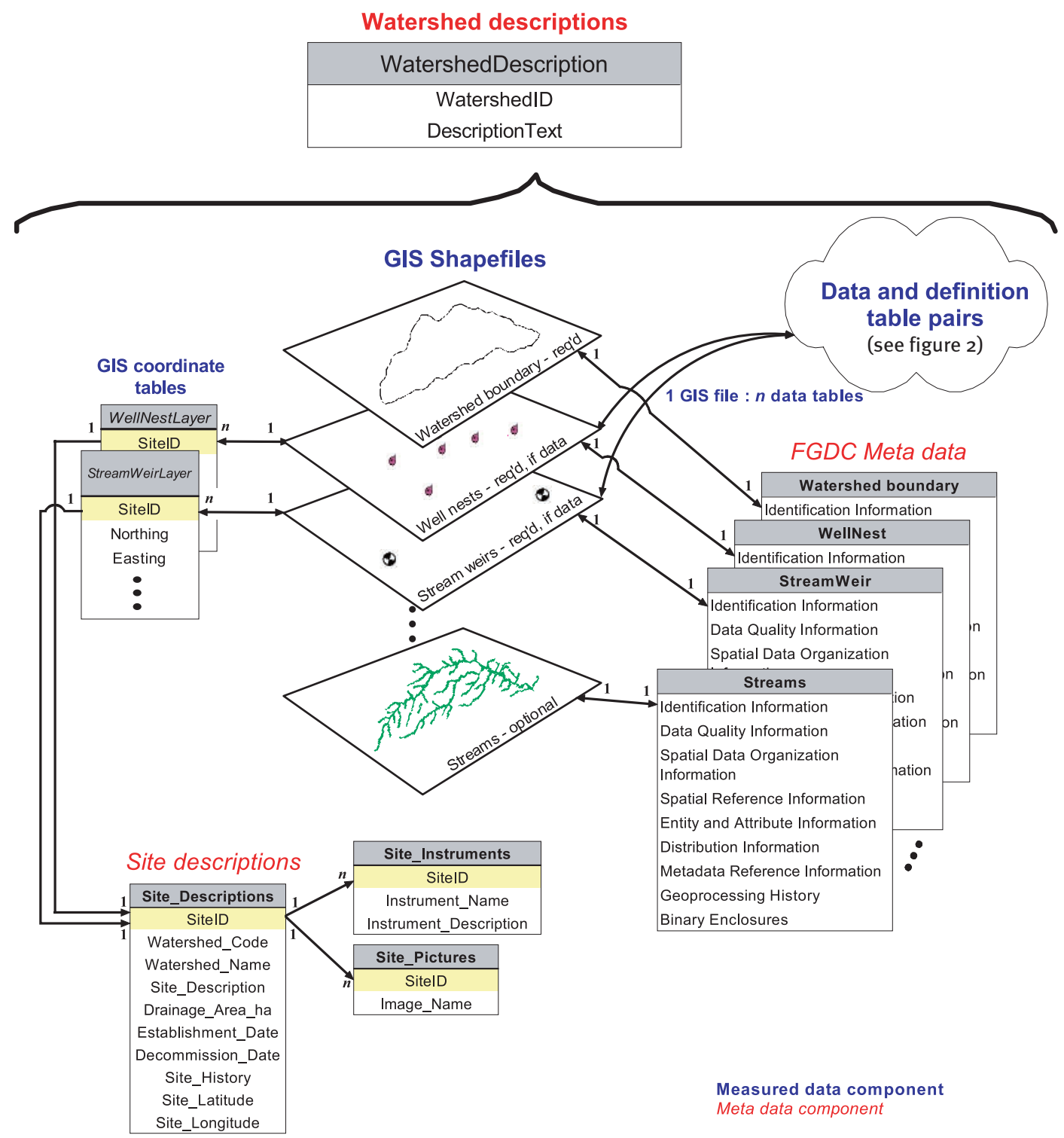

Note: Links indicate the relationships among files, tables, and records. Numbers on links indicate whether the relationship are 1:1 or 1:many (denoted by $n$ ).

domain are shown in figure 1 . At the highest level within the database, each watershed in STEWARDS requires a single file summarizing all aspects of the watershed. This file provides an overview of the physical characteristics and agricultural setting of the watershed, identifies the agricultural research objectives and approaches used by USDA ARS scientists working in the watershed, provides selected references, and identifies cooperators and collaborators partnering in the USDA ARS research and technology transfer efforts.
Within the watershed, spatial data are organized around ArcGIS shapefiles, one layer per file. Sites for individual research data types are shown in these files, which are linked to site descriptions and metadata. These files will vary in number and internal locations depending on the type and amount of data collected by the local watershed team. The uppermost layer shown in figure 1 is required to define each watershed boundary. Measurement table pairs require a corresponding geographic information system (GIS) file showing the sites for which that measurement is made, such as for well nests and stream weirs in figure 1. Beyond the required watershed boundary and measurement location files, several more files can be added to help understand the data, but these are not required. Some that could be included are a digital elevation model, soil map, maps of land use (public information only), or stream network map (as shown in example). Most of these additional files are available from other sources but generally will have been assembled and trimmed to the watershed boundaries by those supplying 
the data. Thus, content users would not need to visit other sites to obtain GIS layers useful for data interpretation or computer simulation runs. Additional layers, such as roads and government boundaries that are used in the STEWARDS display are generally obtained via Internet mapping Web services but provide valuable contextual information to the STEWARDS user. All GIS files require associated Federal Geospatial Data Committee (FGDC)-compliant metadata as shown in figure 1 (FGDC 1998).

To effectively describe measurement data, STEWARDS stores information about the data (metadata) separately, not as part of the data. Descriptive metadata for spatial data include the location, geographical setting, instrumentation, and perhaps images found at each measurement site and specific information regarding the spatial data files used in the project. These metadata enhance the end users' understanding of the measurement data.

The SiteID is critical to linking the spatial and temporal domain and for linking within each of those domains. The SiteID provides an organizational structure to support queries, displays, and metadata based on location. While at first glance straightforward, defining SiteID is complicated by the considerable local flexibility provided to the watershed managers regarding the definition of a site. The SiteID may refer to a point, an area, or an assemblage of topically related points spread over a definable area. Thus, 'site' should be considered a general rather than a specific term. Ultimately, how sites are identified depends on how the local researchers view their own data and how those data would be packaged for downloading by others. As a practical matter, any single SiteID has a direct relationship with a map point used for displaying data in the STEWARDS interface and also with a site description record (shown in figure 1). Thus, careful consideration prior to converting a local watershed's data may pay benefits in converting, building supportive materials, and communicating the data to users.

Some examples of different data types, their characteristics, and how they were organized in STEWARDS may illustrate this point more easily. In most watersheds, each rain gauge has a unique SiteID with its own description record. Most researchers would consider rain gauges as independent measurements, and perhaps would expect users to request data from some, but not necessarily all gauges at once. Thus, having each gauge as a separate site is preferable to combining them. A contrasting example is a series of well nests, with wells at multiple depths within each nest. Generally speaking, distances between wells within nests are small compared with distances between nests, and most researchers requesting data will desire data from all depths at a single location. While each individual well is a specific object in space, that distinction is not terribly important to most users. Thus, a unique SiteID for each nest cluster might be advantageous from both the researcher's and the user's perspectives. An additional column in each of the data table, the GIS layer, and site description distinguishes individual wells within the nest. Continuing the pattern of aggregation, multiple soil samples are commonly taken within a field for many projects. The sampling sites are necessary to locate where the data were taken, but no persistent apparatus exists in the field. In these cases, the methods applied at each sub-SiteID are the same. Further, anyone desiring any of these soil sample data will likely desire all of them. Thus, having all soil sampling locations stored under a single SiteID is logical The flexibility of the STEWARDS design allows researchers to present their locations as appropriate.

The site description tables provide potential users of the data an appropriate context by which to interpret the data available in STEWARDS. These tables would include general information about the site, its location, information about the measurements taken, the instruments used, and perhaps a photograph. This information is stored in the site description database, with a record for each SiteID and a record for each instrument, plus picture file names, if provided. Information in these site description tables is retrieved and presented in the site description reports generated by STEWARDS.

As mentioned above, the STEWARDS ArcGIS interface uses a single GIS file for each measurement type, or theme, to display locations where measurements are made. Each shapefile maintains its own attribute table in addition to the associated measurement tables. The shapefile attribute table contains, at minimum, the SiteID and the coordinates of the points associated with the site. If needed, additional columns may be added to a layer's attribute table to carry ancillary data.
Each shapefile has an associated metadata file, which must comply with the FGDC standards for metadata. Within ArcGIS, the ARCCatalog tool facilitates building this file. Several other metadata editing tools are publicly available on the Internet. It should be noted that FGDC metadata elements have places to store information about measurements available at a site, whom to contact, and other information regarding data distribution. The GIS metadata, the narrative site description, and entries in the methods catalog collectively comprise the metadata about each watershed's measurement data. The metadata are also the means by which automated harvesting would allow STEWARDS metadata elements to move to the Geospatial One-Stop metadata warehouse (Geodata. gov 2008) where they would be widely accessible.

Temporal Data. Each GIS file has many relationships with data and definition table pairs (figure 1), and the linkage among elements is referenced in figure 2. Figure 2 shows the generic contents of the data and definition table pairs, displays how they are related to the metadata specific to temporal data methods and analytes measured, and provides an example to illustrate specific contents. Details of the definitions of field names are not provided here (see STEWARDS Web site for documentation), but enough of the field names are suggestive that the reader can gain an appreciation of the level of detail provided.

The minimum structure for STEWARDS includes a date/time value, a SiteID, and a parameter description for each data measurement record (Steiner et al. 2008). These three values are the keys for the database to locate information requested by an end user. The date/time value is stored as a standard date-time field rather than in separate fields for year, month, day, hour, and minute. The use of a date-time format allows for queries that extract a portion of the period of record for the entire database. The SiteID was described in the discussion about the spatial data above. The other required element, parameter description, also needs substantial explanation.

The parameter description is a collection of descriptive terms that together provide a brief summary of the individual measurement data fields found in the database. The purpose of the parameter description is to summarize the measurement field in a 


\section{Figure 2}

Measurement-level data tables and metadata components of STEWARDS.

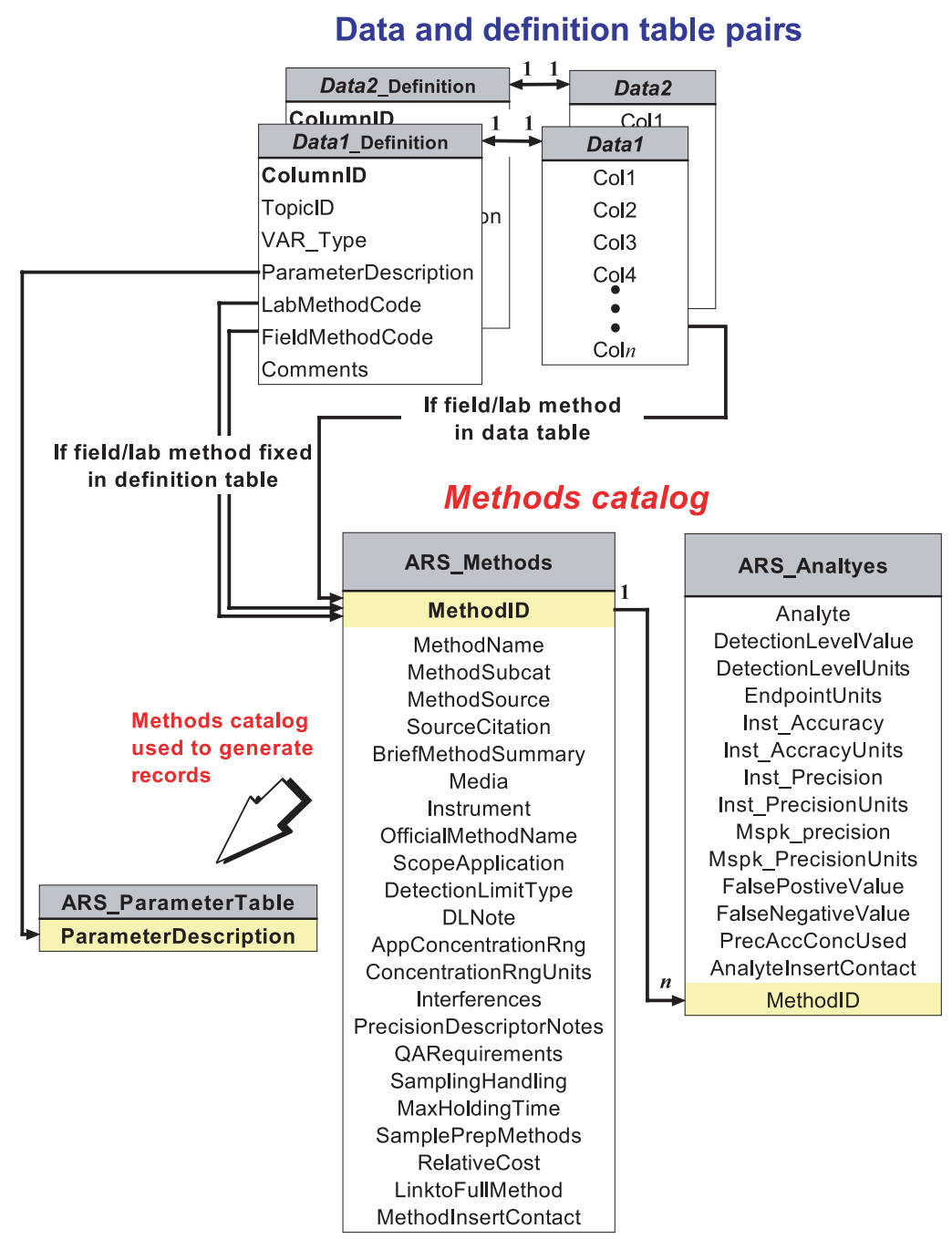

Example: Data and definition table pair

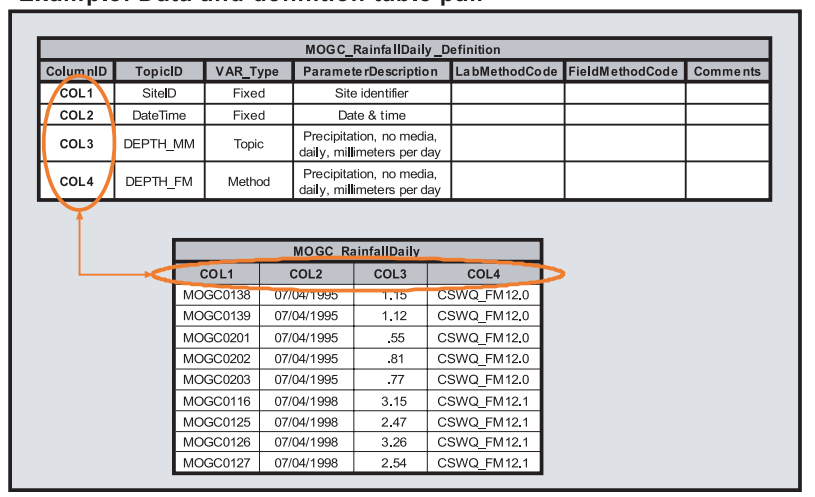

Note: Links indicate the relationships among tables, records, and columns, with numbers indicating 1:1 and 1:many as in figure 1. consistent format and to present the data producer and the user with a standardized reference for measurement data. The parameter description consists of three required descriptors (measurement parameter, sample medium, and reporting units), an optional parameter name modifier, and three optional modifiers (temporal resolution, summary statistic, and ad hoc). All elements of the parameter description are separated by commas. In the format listed below, the optional modifiers are shown within square brackets, []:

parameter name, [parameter name modifier], medium, [temporal resolution], [summary statistic], [ad hoc modifier], reporting units

The optional parameter name modifier can provide additional information about the parameter name. The temporal resolution modifier identifies the time basis, generally in response to a statistical summary; e.g., hourly, daily, or monthly. Grab samples or other instantaneous measures could be identified as instantaneous or the modifier could be left off. Note that this last alternative is why the temporal resolution modifier is optional; the time basis would be necessary for summary statistics. The Summary Statistic modifier pertains to the method of summarizing sample values for reporting; e.g., mean, minimum, maximum, or sum. Ad hoc modifiers would follow the Summary Statistic and precede the reporting unit declaration. If optional modifiers are not used, the modifier field and comma are skipped. The full reporting unit name (e.g., milligrams per liter) is used to avoid ambiguity. Words rather than symbols or superscripts are used. The first letter of parameter description is capitalized and lower case letters are used for the rest except in the one case where SI usage dictates (degrees Celsius). Examples of a range of parameter descriptions are shown in table 1 .

Data and Definition Tables. The actual data within STEWARDS are located in a suite of paired tables (data table and data definition table [figure 2]). These tables are assembled and populated by personnel at each watershed site. All of the data will be managed as a collection of sites with a common theme reflecting the type of measurement or information (e.g., South Fork 
Table 1

Selected parameter description components presented to illustrate the range of options available to describe measurements within STEWARDS.

\begin{tabular}{|c|c|c|c|c|c|c|}
\hline $\begin{array}{l}\text { Parameter } \\
\text { name }\end{array}$ & $\begin{array}{l}\text { Parameter } \\
\text { name } \\
\text { modifier }\end{array}$ & Medium & $\begin{array}{l}\text { Temporal } \\
\text { resolution }\end{array}$ & $\begin{array}{l}\text { Summary } \\
\text { statistic }\end{array}$ & $\begin{array}{l}\text { Ad hoc } \\
\text { modifier }\end{array}$ & Reporting units \\
\hline Atrazine & & Water & & & & Micrograms per liter \\
\hline Nitrate-N & & Water & & & & Milligrams per liter \\
\hline Orthophosphate & & Water & & & & Milligrams per liter \\
\hline Phosphate & Total & Water & & & & Micrograms per liter \\
\hline Stage & & Water & Instantaneous & & & Meters \\
\hline Stream discharge & & Water & Daily & Mean & & Cubic meters per second \\
\hline Temperature & & Air & Daily & Maximum & & Degrees Celsius \\
\hline Temperature & & Soil & Hourly & Average & $5 \mathrm{~cm}$ & Degrees Celsius \\
\hline Wind direction & & Air & Daily & Mean & & Azimuth in degrees from north \\
\hline
\end{tabular}

Note: Italics indicate those parameters may not exist for all measurements, as indicated in the text. In practice, these components are concatenated (i.e., separated by commas) to build a full parameter description.

meteorology - temperature, rainfall, atmospheric pressure, wind, etc.). Measurement data from each site will be managed by unique SiteID/DateTime pairs and, in the case of collective data, one or more additional sub-SiteIDs, as described above, to distinguish unique points in the collection. Measurements in the data table are identified in additional column headings using generic column names mapped to detailed information in the definition table, which will maintain the relationship between the data producer's data-table specific column names and the system metadata. An example illustrates this pairing in the figure 2 inset.

The relationships among each data table, data_definition table, the methods catalog, and the parameter description are briefly summarized as follows. The data_definition table allows each watershed to define data tables according to their own requirements. Each column of the data table has an associated record in the data_definition table.This record "defines" the columns of the data table. All measurement columns in the data table are also associated with a parameter description field in the applicable record of the data definition table. Furthermore, for each measurement column, there may be a field method and a lab method entry in the methods catalog. If the same method is used for an entire period of record, that method can be specified in the data_definition table record for the measurement. If a method varies during the period of record, it should be added as a column in the data table, just after the measurement column. (The example in figure 2 uses this approach). This flexibility was needed within STEWARDS because while some newer watersheds can choose the former scenario (defining methods in the data_definition table), the older watershed research sites will most likely have had changes in methods over time and will need to include the specific methods in the data file.

Data tables require several companion files to be fully described in STEWARDS. Required files, in addition to the abovedescribed data_definition table, are a GIS file, and an FGDC compliant metadata file (figure 1). Each data table also requires records in site description tables (figure 1), methods tables (figure 2), and parameter name description tables (figure 2). The methods catalog tool in STEWARDS is used to generate the Parameter Description to assure consistent format.

Accessing Data in STEWARDS. Accessing data from STEWARDS uses an interface and query procedure for the STEWARDS database. Examples are given for both the national level and for a specific watershed.

National Map Level. The national screen of the STEWARDS interface has four main areas (figure 3). Area A, typical of GIS interfaces, is a toolbar that allows the user to (from left to right) zoom in, zoom out, pan, return to full extent, select a location, and measure. The zoom in/out operation can be achieved several ways. If either of the icons is high- lighted, a single mouse click causes a zoom in that direction, with the center of the new map at the point of the click. If the zoomin icon is highlighted, a box can be created to define the next extent. If the zoom-out icon is active, clicking and dragging a box simply zooms out. Also, the roller wheel on a mouse causes zoom in and out with the center fixed.

Area B contains standardWeb menu links to go to the USDA ARS Web site for the Water Resource Management National Program, to display the contributors to STEWARDS, or to obtain help. Selections in area C (shown in table 2) and the sites identified in area D are specific to the STEWARDS database.

Watershed Level. Once a specific watershed has been chosen (figure 4), the area mapped is changed from the national map (figure 3) to the extent of the chosen watershed. The item "Map Contents" identifies the data and ancillary layers available for the watershed. These layers can be deselected to remove them from the map display using standard GIS conventions, including unchecking the box, or expanding to see details and un-checking individual boxes at more detailed levels. A bar in the map area allows the watershed description to be viewed. The fifth icon in toolbar A can now be used to select sites within the watershed. At this watershed map level, the area below "Map Contents" now has additional panels for more detailed searches. These choices, along with a description of what can be expected to occur, are explained in table 3 . 


\section{Figure 3}

Main screen of STEWARDS.

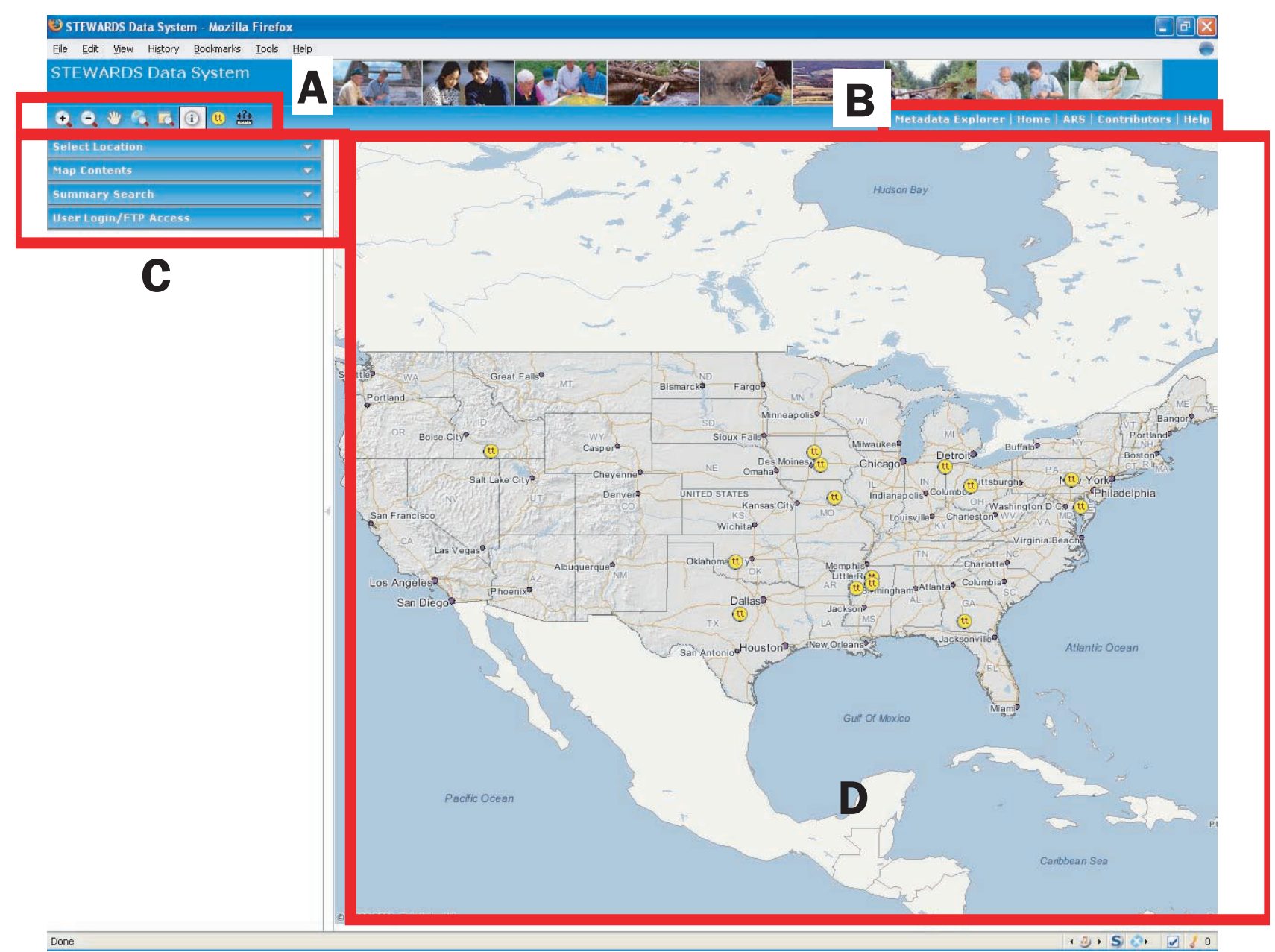

Notes: Toolbars and menu items are labelled for reference in text. This screen shows all watershed locations and allows the user to select one watershed for further study. 


\section{Table 2}

User selections and resultant actions caused by potential choices available within area C (figure 3) of the STEWARDS main screen.

\begin{tabular}{ll}
\hline Selection & Action \\
\hline Select location & This opens a drop-down box to select locations by name. Choosing one takes the user to the watershed level described below.
\end{tabular}

Map contents

This shows the active and inactive layers of the map in area D. The location points, if expanded by clicking on the + , show the symbols for the CEAP watersheds in one layer, and the watershed names and colors mapped to them in another. The base map can be expanded to show a number of publicly available data layers provided.

Summary search This opens a dialog box with two additional selections for simple and advanced searches.

Simple word search A free-text search of the parameter database.

Advanced search A search with a drop-down box of existing topics in the database, and allows selection of time-step, duration, and beginning and ending dates.

Login

This allows the user to log in, which is required for download access.

Of the choices in table 3 , choosing site specific search delivers the screen shown in figure 5 , and choosing parameter search delivers the screen shown in figure 6. From either of these two, choosing "Get Data" and expanding the panel (figure 7) provides a tabular visualization with the four choices shown in table 4.

Visualizations are in tabular form (figure 7) or graph form (figure 8), and the metadata are available to anonymous users. However, downloading data requires registration of users (note the disabled button labelled "download" in figure 7). In the lowerlefthand corner of the screen shown in figure 7, a panel labeled "User Login/ FTP Access" has options for new users and existing users to download data. New users must enter an e-mail address, their name, and their organization. Existing users returning to STEWARDS need enter only their e-mail address. Users who have previously logged in will see their e-mail address on the "Existing User Download" panel (figure 7), and the download function is enabled in the central search output window. Choosing that download option produces the popup window seen in figure 9. From this popup window, using one of the two save-as options, the tabular data can be requested in text format or Excel file format.

Users who have requested a downloaded dataset using the choices in figure 9 will always receive (1) a header page describing the contents, (2) the data table of selected items, (3) the data_definition table matching the data table, (4) the relevant records from the methods table, and (5) the FGDCcompliant metadata (even if the GIS layer is not requested). The user can also choose options to obtain the watershed GIS files, the site description reports, and the watershed description file.

One other type of download (see "direct data access using ftp" selection) is available from the login screen in figure 7 . In many cases, suites of data are commonly needed, such as the collection of files for a calibration and validation run for the Soil and Water Assessment Tool (SWAT) model. If a data provider chooses, the complete ensemble from their watershed can be combined into a single file and stored on the STEWARDS FTP site for download en masse. The potential data available depend on the choices made by watershed researchers and data managers.

STEWARDS System Management. Management of the STEWARDS database occurs at two levels. Operational management includes database administration functions, software development, and system administration. Strategic oversight is performed by a steering committee comprised of researchers, research leaders, and IT professionals. Each of these management functions are described in more detail below.

Operational Management. Database administration responsibilities will focus primarily on maintaining the measurement, spatial (GIS), and metadata databases that will be housed in the STEWARDS system. The database administrative staff will perform the full suite of standard administrative tasks, such as data loading, backups, and quality assurance. They will also build and maintain the system tables within the database necessary to support the STEWARDS interface.

The software developers for STEWARDS are responsible for overall software design, development, and maintenance, and software maintenance. Additionally, the staff will provide training to watershed data producers (scientists, lab managers, field technicians, and IT specialists) on the overall STEWARDS design, required table structures, database development tools, and software components available to prepare data prior to uploading. Once the data tables have been uploaded by the watershed data managers, the STEWARDS database administrators will import the data tables, provide quality assurance of the data format, and update the summary tables to reflect new uploads. Other responsibilities include maintaining the software test plan, debugging the software, and designing and coding fixes and modifications. In addition, the software developers work with the database administrators in identifying, designing and coding upgrades; Web site configuration management; and database design documentation.

Overall computer system administration is provided by the system administrator whose role primarily focuses on the server environment, network communications, and Internet security. This role includes maintaining the operating system through migrations, upgrades, and patches, as well as dealing with hardware failures. It also includes maintaining the design documentation for the hardware, the operating system, the communications, and the security plan. The system administrator must coordinate with the other administrators during fault and failure recovery.

Strategic Oversight. The strategic oversight provided by the steering committee 
Figure 4

STEWARDS screen after selecting the South Fork lowa River (lowa) watershed for examination.

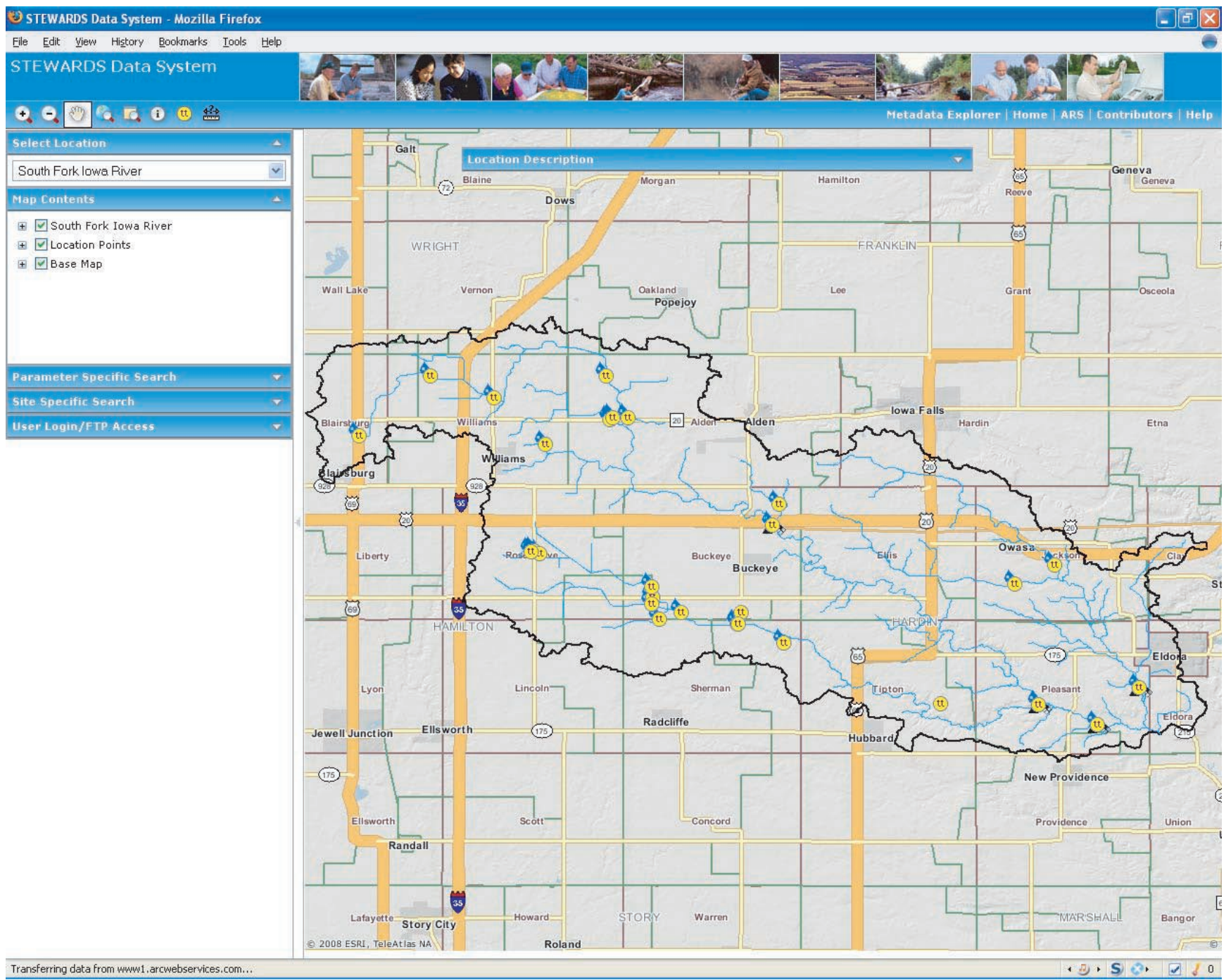

Note: The user can see sites where data exist for all measurements made. 
Table 3

Additional search options that become available once a user has selected a specific watershed for further evaluation.

\begin{tabular}{|c|c|}
\hline Selection & Action \\
\hline Parameter specific search & This opens a dialog box with the choices below (see figure 6). \\
\hline Parameter list & Shows all parameters available in the watershed. \\
\hline Source table list & Active only after a parameter is chosen, it lists what source tables in the watershed data include the parameter. \\
\hline Site list & $\begin{array}{l}\text { Active only after a source table is chosen, it lists all sites within the watershed with the parameter and } \\
\text { source table chosen above. }\end{array}$ \\
\hline Begin date/time & Shows the earliest data for all sites, or in a specific subset of sites if chosen. \\
\hline End date/time & Shows the latest data for all sites. \\
\hline Get data & $\begin{array}{l}\text { Clicking this button causes a new bar in the map area. Expanding it shows a table of data by page with } \\
\text { five new choices. See below for explanation. }\end{array}$ \\
\hline Site specific search & $\begin{array}{l}\text { This search limits the selection of one site, and would be used to find all types of data measured at one specific site. } \\
\text { The search displays a floating panel in the map area with the site description. It also opens a dialog box with SitelD } \\
\text { identified and the choices below (see figure 5) }\end{array}$ \\
\hline Source table & Lists the tables with data obtained at or associated with that SitelD. \\
\hline Parameter list & Active only after the source table has been chosen, it lists parameters available at the SitelD. \\
\hline Begin date/time & Shows the earliest date for all sites, or in a specific subset of sites if chosen. \\
\hline End date/time & Shows the latest date for all sites, or in a specific subset of sites if chosen. \\
\hline Get data & $\begin{array}{l}\text { Clicking this button causes a new bar in the map area. Expanding it shows a table of data by page with } \\
\text { five new choices. See below for explanation. }\end{array}$ \\
\hline
\end{tabular}

is an extension of the functions provided by the team that designed and developed STEWARDS. Functions include evaluating existing and additional requirements, managing the interface of STEWARDS with other research initiatives, establishing and maintaining staffing and funding for the system management, maintaining the system requirements documentation, evaluating consistency of nomenclature and data content, and evaluating and reporting system performance and usefulness.

Next Steps. At the time of this writing there are two modifications planned for the STEWARDS database: developing an online help and user manual and adding secured locations where users can upload or access confidential data in a protected environment. In addition, the management team expects to receive requests for other upgrades that will have to be considered by the steering committee and system administrators. By design, there will be continual uploading of data as watersheds prepare it for STEWARDS.

\section{Summary and Conclusions}

Recognizing that access to watershed-scale research data was essential to successfully carry out mandates associated with the CEAP (Mausbach and Dedrick 2004), a team of researchers and IT personnel were tasked to develop a system where data from long-term research locations could be stored and retrieved. The overall system and process associated with developing the STEWARDS data system are described by Steiner et al. (2008). The description of the STEWARDS database utilizes different components so that each watershed can incorporate their methods for data collection and data elements in a geo-referenced approach. The user operations include data entry and retrieval and are linked to the oversight and management plan for the data as a means of increased potential utilization of the data within and among research programs. Development and release of the STEWARDS data system will make long-term historical and future data collections from watersheds much more available for addressing national and international challenges affecting our natural resources and those who depend upon them. 


\section{Figure 5}

STEWARDS screen after requesting a site-specific search within the North Walnut Creek (lowa) watershed.

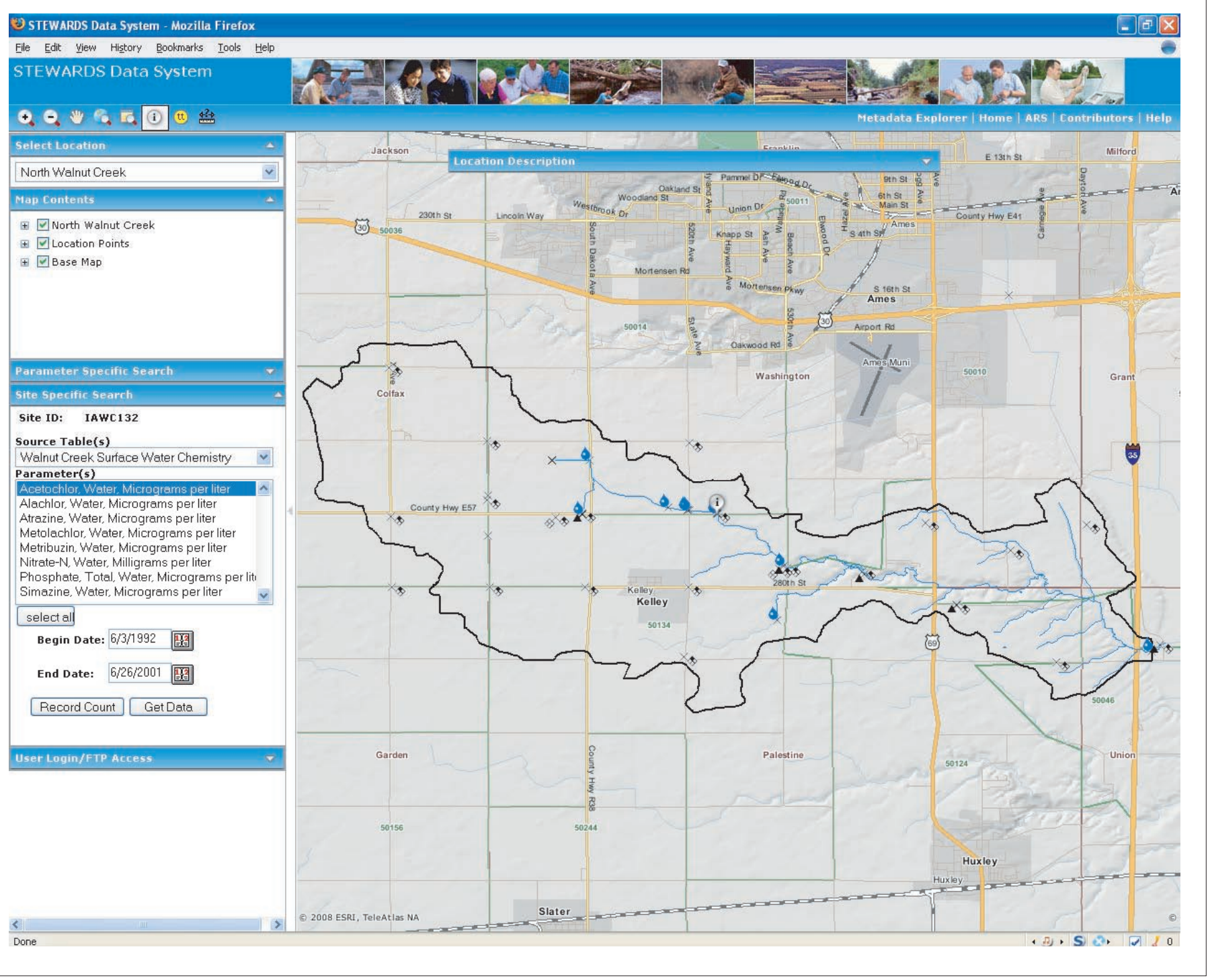


Figure 6

STEWARDS screen with a parameter-specific search within the Mahantango Creek (Pennsylvania) watershed.

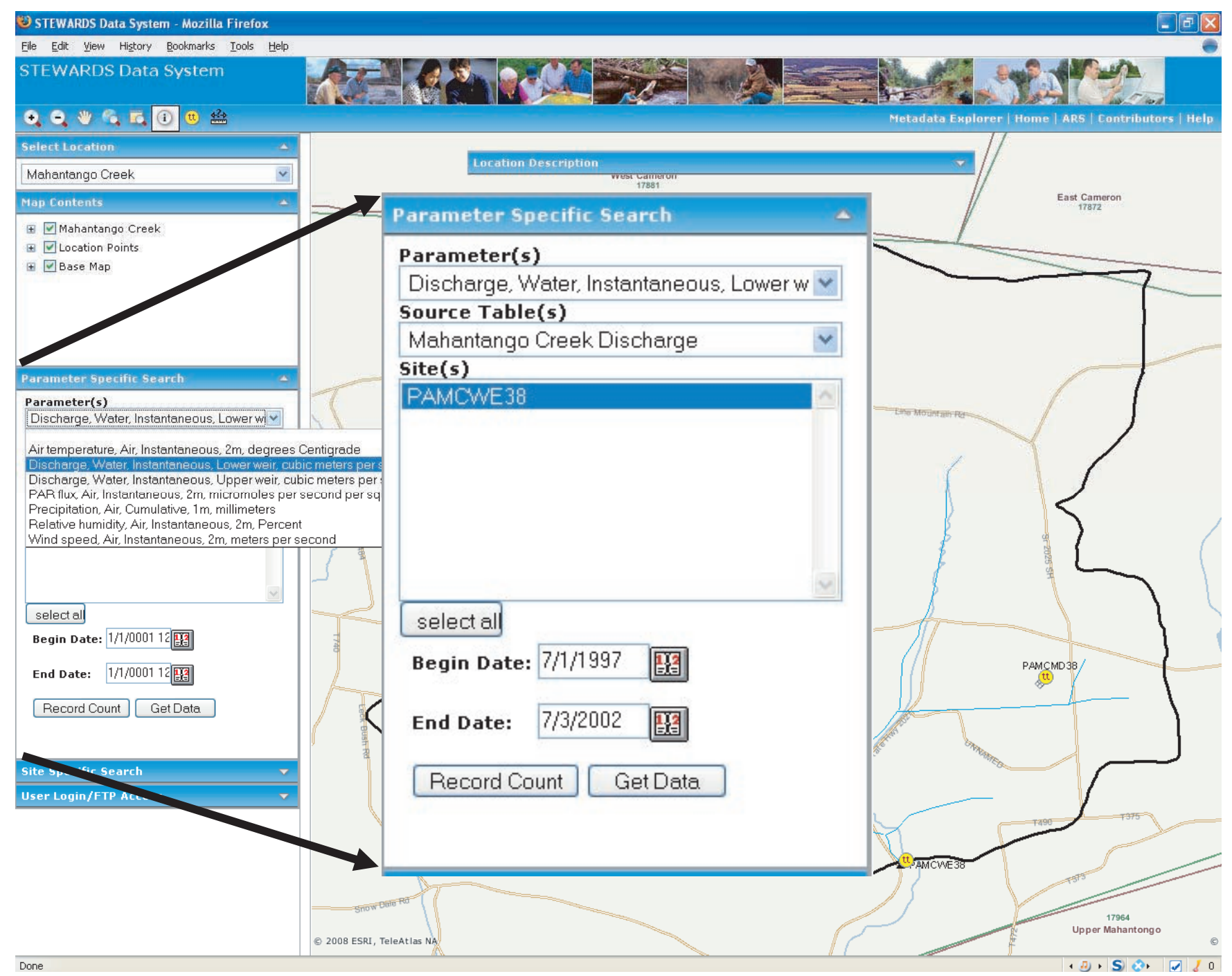

Note: The inset shows the further result after the user has selected one parameter and source list. 


\section{Figure 7}

STEWARDS screen after a query for atrazine concentration in Goodwater Creek (Missouri) watershed, showing tabular visualization of data.

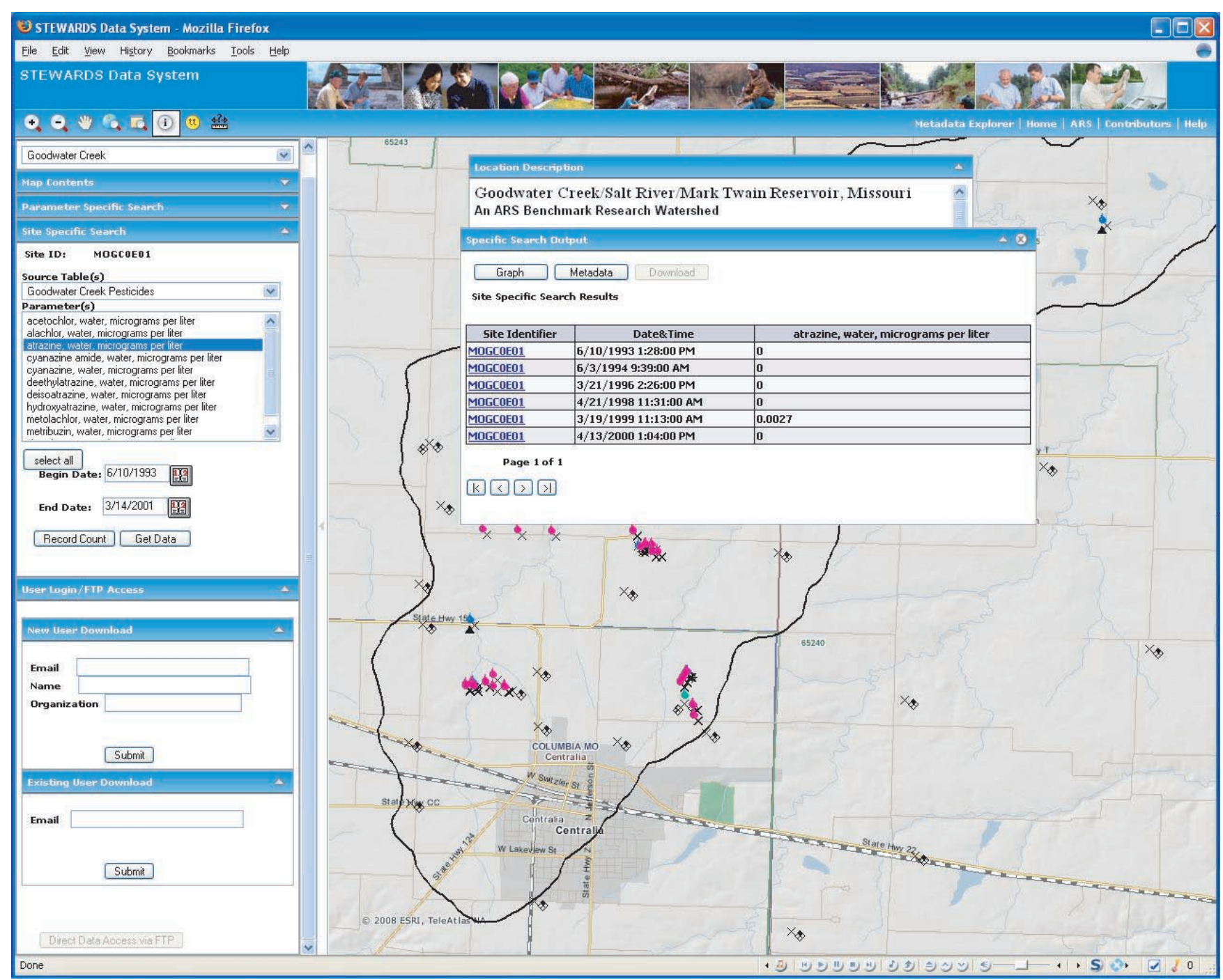

\section{Table 4}

Options for visualization and downloading of data displayed only after a user has defined a specific search within STEWARDS.

\begin{tabular}{ll}
\hline Selection & Action \\
\hline Next page/previous page & Page forward and back through the data. \\
First page/last page & Move to the first or last page of the data. \\
Graph & $\begin{array}{l}\text { Shows a graph of data for visualization of the time series } \\
\text { (see figure 8). }\end{array}$ \\
Metadata & $\begin{array}{l}\text { Opens a window showing the Federal Geospatial Data Committee- } \\
\text { compliant metadata in one of the common presentation formats. }\end{array}$ \\
Download & Opens dialog to register the user and download data (see figure 9).
\end{tabular}




\section{Figure 8}

STEWARDS graphical visualization after a query for stream discharge in South Fork lowa River (lowa) watershed.

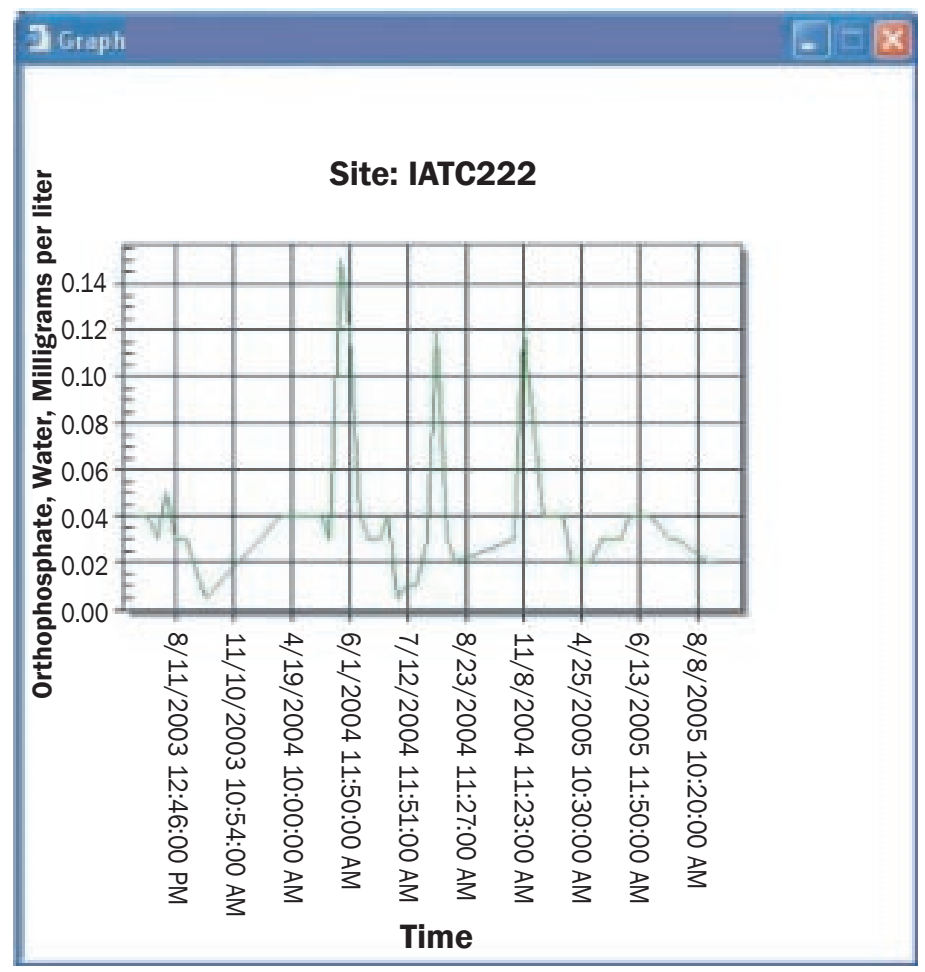

\section{Disclaimer}

Use of trade names is for informational purposes and does not imply endorsement by the USDA Agricultural Research Service.

\section{References}

FGDC (Federal Geographic Data Committee).1998. FGDCSTD-001-1998. Content standard for digital geospatial metadata (revised June 1998). Federal Geographic Data Committee, Washington, DC.

Geodata.gov. 2008. US Maps \& Data. http://gos2.geodata. gov/wps/portal/gos.

Mausbach, M.J., and A.R. Dedrick. 2004. The length we go: Measuring environmental benefits of conservation practices. Journal of Soil and Water Conservation 59(5):96A-103A.

Steiner, J.L., D.C. Goodrich, S. Hardegree, M.R. Burkhart, T.C Strickland, and M.A. Weltz. 2003. Information technology applications in the ARS watershed network. In First Interagency Conference on Research in the Watersheds, ed. K.G. Renard. October 27-30, 2003. US Department of Agriculture, Agricultural Research Service.

Steiner, J.L., E.J. Sadler, J.-S. Chen, G. Wilson, D. James, B. Vandenberg, J. Ross, T. Oster, and K. Cole. 2008 Sustaining the Earth's Watersheds-Agricultural Research Data System: Overview of development and challenges. Journal of Soil and Water Conservation 63(6):569-576.

USDA Agricultural Research Service. 2008. Sustaining the Earth's Watersheds-Agricultural Research Data System (STEWARDS). http://arsagsoftware.ars.usda. gov/stewards/

\section{Figure 9}

Dialog box for a download session with a user who has logged in. If the user had not logged in, this screen would not be accessible.

\begin{tabular}{l} 
Aser username@domain is logged in, record count \\
is 5872 \\
Additional Download Options \\
$\square$ Watershed GIs Files \\
$\square$ Site Description (HTML) \\
$\square$ watershed Description (HTML) \\
$\square$ \\
Save to Text File (tab delimited) \\
\hline Done
\end{tabular}

